\title{
Lithium salts as a marker of intake of supplements by cattle
}

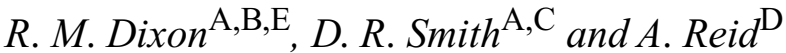 \\ A Agency for Food and Fibre Sciences, QBII, Swan's Lagoon Research Station, Millaroo, Ayr, Qld 4702, Australia. \\ BPresent address: Agency for Food and Fibre Sciences, QBII, Department of Primary Industries, \\ PO Box 6014, Rockhampton, Qld 4702, Australia. \\ ${ }^{C}$ Present address: Agency for Food and Fibre Sciences, QBII, Department of Primary Industries, \\ Charters Towers, Qld 4820, Australia. \\ DAgency for Food and Fibre Sciences, QBII, Department of Primary Industries, \\ Abbott St, Oonoonba, Townsville, Qld 4811, Australia. \\ ${ }^{\mathrm{E}}$ Author for correspondence; e-mail: rob.dixon@dpi.qld.gov.au
}

\begin{abstract}
In a series of experiments the appearance of lithium cation in plasma following ingestion or intravenous administration of lithium salts was measured in order to examine the suitability of lithium as a marker of supplement intake by cattle. In experiment 1, cattle were offered low quality hay ad libitum and $0.15,0.4,1.0$ and $3.0 \mathrm{~kg}$ cottonseed meal (CSM) supplement per day. Following ingestion of lithium-labelled CSM, the lithium concentration in plasma reached a maximum after about $24 \mathrm{~h}$ and the subsequent decrease in concentration appeared to follow a single exponential relationship. The rate constant of this disappearance of lithium from plasma was greater $(P<0.05)$ when $3.0 \mathrm{~kg}$ than when lesser amounts of lithium-labelled CSM were consumed. Plasma lithium concentrations 24 and $32 \mathrm{~h}$ after ingestion of lithium-labelled CSM were both linearly related to the amount of supplement consumed ( $r=0.86$ and 0.87 , respectively, $n=32, P<0.001$ ), indicating that the plasma lithium concentrations could be used to measure intakes of supplement by individual animals. In experiment 2 , following intravenous administration of lithium chloride the disappearance of lithium from plasma over $96 \mathrm{~h}$ appeared to be best described by 3 exponential compartments. In experiment 3, cattle were offered molasses-based or loose mineral mix (LMM) supplement, or water, labelled with lithium and the rate constant of disappearance of lithium from plasma between 32 and $96 \mathrm{~h}$ was determined. The pattern of the decrease in plasma lithium concentration was similar to that observed in experiment 1 . In experiment 4 , the variation about the estimates of supplement intake was measured in heifers $(n=24)$ offered hay and water ad libitum and in addition a meal of $60 \mathrm{~g}$ of lithium-labelled molasses-urea supplement; between 20 and $28 \mathrm{~h}$ after ingestion of the lithium-labelled supplement the coefficient of variation (CV) among animals in plasma lithium concentration was about $15 \%$. The likely errors associated with the use of lithium salts to measure intake of supplement are discussed. These experiments confirm that lithium salts can be used as a marker to estimate intake of supplement by individual animals.
\end{abstract}

\section{Introduction}

Supplements are often provided to grazing ruminants to supply nutrients that are likely to be insufficient in pasture, but it is often difficult to achieve intended intakes of supplement by all individual animals in a herd or flock. Many animals may not consume any supplement, while among those that do consume there may be high variability in supplement intake (Arnold and Maller 1974; Nolan et al. 1975; Murray et al. 1978; Eggington et al. 1990; Bowman and Sowell 1997). Variability in intake of supplements is likely to be particularly high when mineral and non-protein nitrogen supplements are provided ad libitum as loose mineral mix or solidified feed blocks to grazing animals (Dixon and Petherick 1996; Dixon and Smith 2000; Dixon et al. 2000, 2001). An understanding of the factors which influence supplement intake by individual animals in a herd or flock is clearly necessary to improve management strategies to achieve target intakes of supplement by all animals and to optimise cost-effectiveness of supplements. However, to investigate such factors suitable techniques are needed to measure intake of supplements by individual animals in groups while grazing.

The roles and efficacy of markers to measure intake of pasture, pasture components, pasture species and supplements have been reviewed (Kotb and Luckey 1972; Langlands 1975; Holechek et al. 1982; Dove and Mayes 1991). Such marker techniques generally depend on the principle of adding a substance to the diet or the digesta, or identifying an unusual component of the diet, a constant proportion of which is excreted by the animal. In particular, marker techniques to measure intake of supplements by grazing ruminants have been recently reviewed by 
McLennan (1999). Tritiated water and deuterium are particularly suitable markers of supplements (Nolan et al. 1975; Rocks et al. 1982; Dove 1984). However, the use of a radioactive substance such as tritiated water is severely constrained by concerns for human health and the environment, while deuterium is costly for large ruminants or large numbers of animals. Digesta markers that are quantitatively excreted in the faeces, such as chromic oxide (Foot et al. 1973; Lobato et al. 1980; Ducker et al. 1981) and ytterbium (Curtis et al. 1994), have been used to measure supplement intake. However, since these markers require either complete collection of faeces for several days (e.g. by collection bags attached to the animals) or important assumptions of forage intake and digestibility, their usefulness is limited. Consequently, the cation of lithium has been investigated as a marker since it has many suitable characteristics. Lithium occurs naturally in the environment, it is harmless to both humans and ruminants at appropriate concentrations, and accurate analysis is simple and economical (Suharyono et al. 1991; Suharyono 1992). Although lithium salts have pharmacological and toxic effects and can cause feed aversion (Du Toit et al. 1991; Suharyono 1992), the amounts necessary to cause these effects in ruminants are much greater than the amounts generally required as a marker. Lithium salts have been used as a marker of supplement intake for grazing sheep (Suharyono 1992; Kahn 1994; Holst et al. 1996) and cattle (Dixon and Petherick 1996; McLennan 1999).

In penned sheep and cattle, plasma lithium concentration has been linearly related to the amount of lithium salt ingested in a supplement (Suharyono 1992; Kahn 1994; McLennan 1999). However, further experimentation is needed to confirm such relationships in cattle and for a variety of dietary and environmental circumstances. Experiments were therefore undertaken to examine lithium concentrations and kinetics in plasma following either ingestion of lithium-labelled supplement or intravenous administration of lithium to evaluate the reliability and accuracy of lithium as a marker of supplement intake for cattle in a tropical environment. Two experiments examined the appearance and disappearance of lithium in plasma following ingestion of various amounts of cottonseed meal (CSM) (experiment 1) or of molasses-urea, 2 types of loose mineral mix (LMM) supplement, or drinking water (experiment 3) labelled with lithium. Experiment 2 examined lithium concentrations in plasma following a single intravenous injection of lithium to measure the kinetics of lithium distribution and excretion. The variability in plasma lithium concentration among cattle offered a hay diet and held under closely controlled pen conditions, and thus of error inherent in the use of lithium as a marker of supplement intake, was determined in experiment 4.

\section{Materials and methods}

Experiment 1. Ingestion of various amounts of lithium-labelled CSM supplement

Ten Bos indicus $\times$ Bos taurus crossbred steers [initially 12-14 months of age, liveweight (LW) mean 217 (s.d. 15) kg and body condition score 3-4 on a 9-point scale (NRC 1996)] were housed individually in partially roofed pens ( 7 by $10 \mathrm{~m}$ ). During 4 consecutive periods each of 14 days, 8 steers were allocated in a repeated Latin Square experimental design to 1 of 4 levels of supplementation with cottonseed meal (CSM) $(0.15,0.40,1.00$ and $3.00 \mathrm{~kg} /$ day $)$. The 2 remaining steers were offered $0.4 \mathrm{~kg} \mathrm{CSM} /$ day during periods 1 and 2 and were offered 1.0 and $3.0 \mathrm{~kg} \mathrm{CSM}$ /day during periods 3 and 4 . All steers were offered low-quality Panicum maximum hay at $20-30 \%$ in excess of actual intake, fresh hay being offered and hay refusals removed and weighed 3 times each week. CSM was offered at 0800 hours each day in a separate feeder. DM content of the offered and refused hay and of CSM was determined by drying at $70^{\circ} \mathrm{C}$. Water was offered ad libitum in drums ( $570 \mathrm{~mm}$ diameter) and water intake was measured daily by change in height of the water in the drums.

On day 8 of each period, the CSM supplement was labelled with lithium chloride (655 mg Li $/ \mathrm{kg} \mathrm{CSM})$ and offered to the steers at 0800 hours. Thus, steers were offered about $0.5,1.3,3.3$ or $9.8 \mathrm{mg} \mathrm{Li} / \mathrm{kg}$ LW. Lithium-labelled CSM was prepared by dissolving the lithium chloride in water $(125 \mathrm{~g} / \mathrm{L})$ and spraying this solution over CSM while it was being mixed in a horizontal paddle feed mixer. The amounts of lithium-labelled CSM remaining 0.5, 1, 2, 3 and $4 \mathrm{~h}$ after the supplement was offered to the steers were measured and any supplement remaining after $4 \mathrm{~h}$ was removed. Blood samples were obtained $0.5 \mathrm{~h}$ before and 4 , $8,24,32,48,72$ and $96 \mathrm{~h}$ after the lithium-labelled CSM was offered to the steers. Blood samples were obtained by jugular puncture using vacutainers containing potassium EDTA as an anti-coagulant. Samples were immediately chilled in iced water, centrifuged ( $3000 \mathrm{~g}$ for $10 \mathrm{~min}$ ) to separate plasma and the plasma stored frozen. Plasma proteins were precipitated $(1 \mathrm{~mL}$ plasma added to $5 \mathrm{~mL} 2 \%$ trichloroacetic acid solution) and lithium concentration in the supernatant resulting from centrifugation was determined using an inductively coupled plasma mass spectrometer (ICPMS) (Model Elan 5000 Perkin Elmer). Steers were weighed at 0730 hours on the day lithium-labelled supplement was offered to the steers.

Net lithium concentrations in plasma were calculated by subtraction of the concentration measured before lithium-labelled CSM was provided (mean $2 \mu \mathrm{g} / \mathrm{L}$ in period 1 ; mean $63 \mu \mathrm{g} / \mathrm{L}$ in periods $2-4$ ). Plots of net plasma lithium concentration against time indicated that for each of the treatments the concentration increased to a maximum about $24 \mathrm{~h}$ after ingestion of the lithium-labelled CSM and thereafter appeared to decline exponentially as observed by Suharyono (1992). Since there were insufficient observations to satisfactorily fit an exponential component between 0 and $24 \mathrm{~h}$, a single exponential equation was calculated to describe the change in net plasma lithium concentration between 24 and $96 \mathrm{~h}$ after ingestion of lithium-labelled CSM. This equation was of the form

$$
C_{\mathrm{t}}=A \mathrm{e}^{-\mathrm{kt}},
$$

where $C_{\mathrm{t}}=$ concentration at time $(t), A=$ the $Y$ intercept at time zero, and $k=$ the slope of the exponential component (Shipley and Clarke 1972). The half-time $\left(T_{1 / 2}\right)$ was calculated as $0.693 / k$.

Data for intake of feed and water, plasma lithium concentration at specific sampling times and the rate constant of disappearance of lithium from plasma were examined by residual maximum likelihood (REML; Patterson and Thompson 1971). Distributional assumptions were assessed by visual inspection of residual and normal probability plots. Paired comparisons between means were made using the protected 1.s.d. test adjusted for various sample sizes. In addition, the relationships between lithium concentrations at specific times and the 
amount of lithium-labelled CSM ingested were examined by regression procedures.

\section{Experiment 2. Intravenous administration of lithium chloride}

Eight of the steers used in experiment 1 continued to be housed in the individual pens, were offered hay and water as described above and were allocated at random to 2 treatments consisting of supplements of either 0.4 or $3.0 \mathrm{~kg} \mathrm{CSM} /$ day. Mean LW was 235 (s.d. 12) kg. After 11 days, the CSM supplements were offered at 0515 hours, the steers were blood sampled at 0600 hours and at 0630 hours a solution of lithium chloride ( $3 \mathrm{mg} \mathrm{Li} / \mathrm{kg} \mathrm{LW}$ in $20 \mathrm{~mL}$ physiological saline) was injected intravenously into the jugular vein. Blood samples were obtained by venous puncture from the jugular vein not used for the injection of lithium chloride on 16 occasions, after about $0.17,0.33$, $0.67,1.0,1.5,2,3,4,5,6,9,12,24,48,72$ and $96 \mathrm{~h}$. Plasma was separated and analysed for lithium as described for experiment 1 .

The net concentration of lithium in plasma was calculated by subtraction of background concentration (mean $40 \mu \mathrm{g} / \mathrm{L}$, corrected during the sampling interval by the rate of disappearance of lithium measured in the respective diets in experiment 1). Concentrations of lithium were then normalised to a common amount of lithium dose $(3.0 \mathrm{mg} \mathrm{Li} / \mathrm{kg} \mathrm{LW})$. From plots of lithium concentration against time it appeared that the decrease in plasma lithium concentrations was best described by 3 exponential components. Thus, an equation of the form

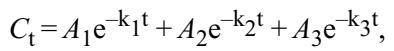

where $C_{\mathrm{t}}=$ concentration at time $(t), A_{1}, A_{2}$ and $A_{3}$ are the $Y$ intercepts at time zero, and $k_{1}, k_{2}$ and $k_{3}$ are the slopes of the 3 exponential components, respectively, was examined. This equation was fitted for each animal observation using manual curve-peeling procedures (Shipley and Clarke 1972). The measurements of intake of feed and water and of the rate constants of disappearance of lithium from the various compartments for the 2 dietary treatments were examined by analysis of variance.

\section{Experiment 3. Ingestion of molasses-urea or loose mineral mix} supplements, or water labelled with lithium

Sixteen steers, LW mean 265 (s.d. 18) kg, consisting of the 10 steers that had been used in experiment 1 and 6 similar animals were housed and managed as described for experiment 1 . Commencing 8 weeks after experiment 2, during each of 2 consecutive 3 -week periods the steers were allocated randomly to 4 dietary treatments. All steers were offered chopped low-quality sorghum hay ad libitum 3 times weekly and, in a separate feeder, various supplements. Water was freely available. Treatment 1 steers were offered ad libitum a supplement of molasses containing $29 \mathrm{~g}$ urea $/ \mathrm{kg}$ (M3U). Treatment 2 steers were offered daily $500 \mathrm{~g}$ cottonseed meal. Treatment 3 steers were offered daily $86 \mathrm{~g}$ of a loose mineral mix supplement containing $(\mathrm{g} / \mathrm{kg}) 568$ chopped lucerne hay, 193 water, 171 urea, 34 molasses and 34 calcium phosphates (LMM-1), while treatment 4 steers were offered $186 \mathrm{~g}$ of a loose mineral mix containing $(\mathrm{g} / \mathrm{kg}) 425$ chopped lucerne hay, 254 sodium chloride, 144 water, 127 urea, 25 molasses and 25 calcium phosphates (LMM-2). During preparation of the LMM-1 and LMM-2 supplements, the molasses and water were mixed separately before being mixed with the other ingredients. Amounts of hay and supplement offered and refused were weighed and subsamples taken for determination of DM content by oven drying at $70^{\circ} \mathrm{C}$.

On day 15 of each period, the M3U (treatment 1), water (treatment 2) or LMM supplements (treatments 3 and 4) offered to the steers between 0800 hours and 1800 hours were labelled with lithium chloride. The lithium chloride was dissolved in water before being mixed with the supplements, the amounts being about $500 \mathrm{mg} \mathrm{Li} / \mathrm{kg}$ M3U, $40 \mathrm{mg} \mathrm{Li} / \mathrm{L}$ water, $12 \mathrm{mg} \mathrm{Li} / \mathrm{g} \mathrm{LMM}-1$ and $6 \mathrm{mg} \mathrm{Li} / \mathrm{g} \mathrm{LMM}-2$. The amounts of lithium-labelled supplement (treatments 1, 3 and 4) or water (treatment 2 ) remaining after $1,2,4,6,8$ and $10 \mathrm{~h}$ were determined by weight or for water by measurement of change in height in the drum in which it was provided. At 1800 hours, the lithium-labelled supplements were removed and non-labelled M3U (treatment 1) or water (treatment 2) provided. Steers were blood-sampled at 0700 hours before the lithium-labelled supplements were offered to determine background concentrations, and then 8, 24, 32, 48, 56, 72 and $96 \mathrm{~h}$ after the lithium-labelled supplements were initially offered. Plasma was centrifuged, stored frozen, protein precipitated and analysed for lithium as described for experiment 1 .

The net concentrations of lithium in plasma were calculated by subtraction of background (mean $4 \mu \mathrm{g} \mathrm{Li} / \mathrm{L}$ ). Concentrations of lithium were then normalised to a common dose of lithium ingested $(5.0 \mathrm{mg}$ $\mathrm{Li} / \mathrm{kg} \mathrm{LW})$. The disappearance of lithium from plasma between 32 and $96 \mathrm{~h}$ after the lithium-labelled supplement was initially offered to the steers was calculated as a single exponential equation. Differences between treatments and periods were examined by 2-way analysis of variance. Paired comparisons between means were made using the protected 1.s.d. test.

\section{Experiment 4. Ingestion of a meal of lithium-labelled molasses supplement}

Twenty-four Bos indicus $\times$ Bos taurus crossbred heifers, 10-14 months of age, LW mean 220 (s.d. 13) $\mathrm{kg}$ and body condition score 5-6, were used in the experiment. The heifers were held in individual pens and offered low-quality speargrass (Heteropogon contortus) hay and water ad libitum. The intake of hay and water was measured as described for experiment 1 .

After 13 days, each of the heifers was, at 1100 hours, offered $60 \mathrm{~g}$ of lithium-labelled supplement which provided about $2 \mathrm{mg} \mathrm{Li} / \mathrm{kg} \mathrm{LW}$. This supplement contained $(\mathrm{g} / \mathrm{kg}) 728$ molasses, 182 water, 68 lithium sulfate monohydrate and 22 urea, and was offered to the heifers in two $4 \mathrm{~g}$ icecream cones manufactured from wheat flour and vegetable oil. Any supplement remaining after $15 \mathrm{~min}$ was removed and the actual intake of supplement was determined from the weights of supplement offered and refused. Blood samples were obtained $0.5 \mathrm{~h}$ before, and 20 , 24 and $28 \mathrm{~h}$ after, the supplements were offered and plasma separated following the procedures described in experiment 1. Lithium concentrations in plasma were determined by atomic absorption spectroscopy (Model Z5100, Perkin Elmer). Net lithium concentrations in plasma were calculated by subtraction of background lithium concentrations (mean $8 \mu \mathrm{g} \mathrm{Li} / \mathrm{L}$ ) and the lithium concentrations were normalised to a common amount of lithium actually ingested $(2.0 \mathrm{mg} \mathrm{Li} / \mathrm{kg} \mathrm{LW})$. Lithium concentrations in plasma at the 3 sampling times were compared by analysis of variance; effects of sampling time were compared within animals.

\section{Results}

\section{Experiment 1. Ingestion of various amounts of lithium-labelled CSM supplement}

The hay contained $892 \mathrm{~g} \mathrm{DM} / \mathrm{kg}$ as fed, $929 \mathrm{~g}$ organic matter and $4.7 \mathrm{~g}$ nitrogen per kilogram $\mathrm{DM}$, and had an in vitro organic matter digestibility of $256 \mathrm{~g} / \mathrm{kg} \mathrm{DM}$. CSM contained $924 \mathrm{~g} \mathrm{DM} / \mathrm{kg}$ as fed, and $928 \mathrm{~g}$ organic matter and $69 \mathrm{~g}$ nitrogen per kilogram DM. The steers were in good health throughout the experiment, had stable intakes of hay and water and always readily consumed their allocations of unlabelled CSM. During periods 1 and 3, all of the steers readily consumed all of the lithium-labelled CSM. During period 2, 2 steers offered $1 \mathrm{~kg}$ lithium-labelled CSM consumed only 3 and $60 \%$, respectively, of this allocation during the $4 \mathrm{~h}$ when it was offered. In addition, during period 4 one of these steers consumed only $91 \%$ of its allocation of 
$3 \mathrm{~kg}$ labelled CSM, while one other steer consumed only $26 \%$ of its allocation of $1 \mathrm{~kg}$ labelled CSM. These 4 measurements were considered as missing values in the analysis. The remaining steers, with 2 exceptions, consumed their entire allocation of lithium-labelled CSM within $1 \mathrm{~h}$; for these 2 exceptions the lithium-labelled CSM was consumed within $3 \mathrm{~h}$. Other than this incomplete consumption of lithium-labelled CSM by some steers, there was no evidence of feed aversion effects or behavioural changes due to ingestion of the lithium-labelled CSM by the steers. Intakes by individual steers of hay and water were similar during the 3 days before and the 2 days after the lithium-labelled CSM were provided. To address the loss of observations described above when some steers did not consume all the lithium-labelled CSM, measurements were made in 2 additional steers during both periods 3 and 4 . By the end of period 4, 8 measurements had been made for the 0.15 and $3.0 \mathrm{~kg} \mathrm{CSM} /$ day treatments, 9 measurements for $0.4 \mathrm{~kg} \mathrm{CSM} /$ day treatment and 7 measurements for the $1.0 \mathrm{~kg} \mathrm{CSM} /$ day treatment.

The intakes of feed and water are shown in Table 1. Hay intake was not changed $(P>0.05)$ by CSM supplementation, but total DM intake was increased $(P<0.05)$ by provision of $1.0 \mathrm{~kg} \mathrm{CSM} /$ day and further increased $(P<0.05)$ by $3.0 \mathrm{~kg}$ $\mathrm{CSM} /$ day. Intake of CSM supplement and total DM was linearly related as follows:

$$
\begin{gathered}
Y=17.4 \text { (s.e. } 0.67)+0.92(\text { s.e. } 0.097) X \\
(n=32 ; r=0.74 ; \text { r.s.d. }=5.34 ; P<0.001),
\end{gathered}
$$

where $Y(\mathrm{~g} / \mathrm{kg} \mathrm{LW}$.day $)$ is the intake of total DM and $X(\mathrm{~g} / \mathrm{kg}$ LW.day) is the intake of CSM. Water intake was increased $(P<0.05)$ by the provision of 1.0 and $3.0 \mathrm{~kg} \mathrm{CSM} /$ day, and tended $(r=0.25 ; P=0.09)$ to be correlated with total DM intake.

The concentrations of lithium in plasma at various intervals after ingestion of the lithium-labelled CSM are

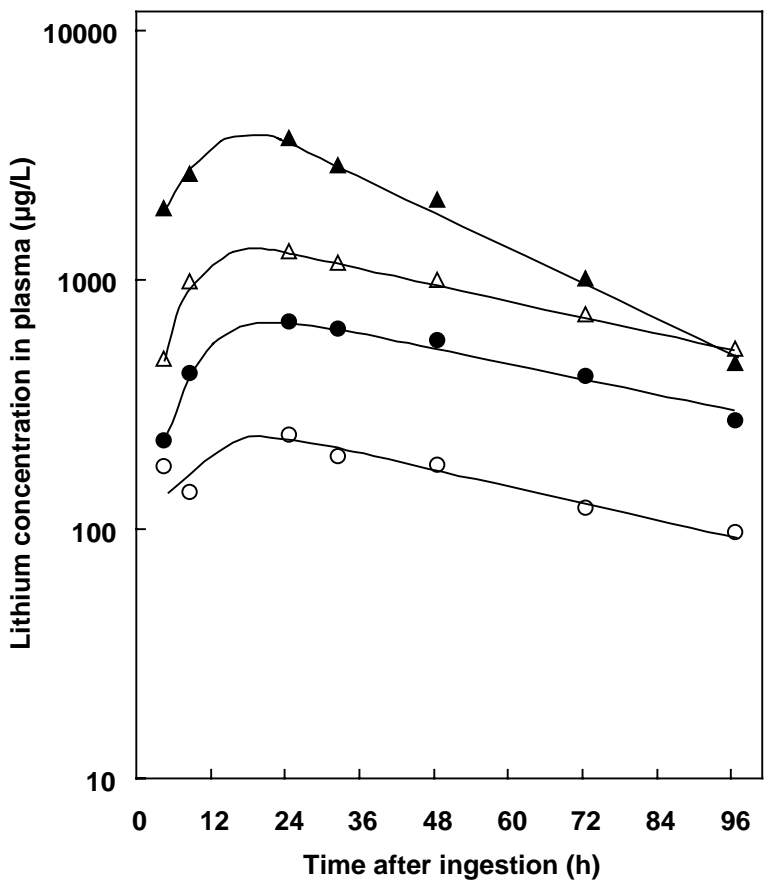

Figure 1. Experiment 1. Mean concentrations of lithium in plasma of steers $(n=7-9)$ consuming low-quality hay and following ingestion of $0.15(\bigcirc), 0.40(\mathbf{O}), 1.0(\triangle)$ or $3.0(\mathbf{\Delta}) \mathrm{kg}$ lithium-labelled cottonseed meal supplement as a single meal.

shown in Figure 1. After increasing to maxima about $24 \mathrm{~h}$ after ingestion of lithium-labelled CSM, the decreases in concentration appeared to be well described as a single exponential relationship. The rate constants for disappearance of lithium from plasma (Table 1) did not differ among the treatments where steers were supplemented with $0.15, \quad 0.4$ and $1.0 \mathrm{~kg}$ lithium-labelled CSM $(0.0117-0.0133 / \mathrm{h})$, but this rate was increased $(0.0258 / \mathrm{h}$, $P<0.05)$ by provision of $3.0 \mathrm{~kg}$ lithium-labelled CSM.

Table 1. Experiment 1. Intake of hay, cottonseed meal (CSM) and total dry matter (DM), and of water by the steers during the 4 days after ingestion of lithium-labelled cottonseed meal

\begin{tabular}{|c|c|c|c|c|c|c|}
\hline \multirow[t]{2}{*}{ Measurement } & \multicolumn{4}{|c|}{ Treatment (kg CSM supplement/day) } & \multirow[t]{2}{*}{ s.e.d. } & \multirow[t]{2}{*}{ Signif. } \\
\hline & 0.15 & 0.4 & 1.0 & 3.0 & & \\
\hline$n$ & 8 & 9 & 7 & 8 & - & - \\
\hline Hay intake (kg DM/day) & 3.57 & 3.63 & 3.87 & 3.44 & 0.178 & n.s. \\
\hline Cottonseed meal intake (kg DM/day) & 0.14 & 0.37 & 0.92 & 2.77 & - & - \\
\hline Total dry matter intake (kg/day) & $3.71 \mathrm{a}$ & $4.00 \mathrm{a}$ & $4.80 \mathrm{~b}$ & $6.22 \mathrm{c}$ & 0.177 & $* * *$ \\
\hline Hay intake (g DM/kg LW.day) & 16.6 & 17.0 & 18.3 & 16.1 & 0.80 & n.s. \\
\hline Cottonseed meal intake (g DM/kg LW.day) & 0.8 & 1.9 & 4.3 & 13.0 & - & - \\
\hline Total dry matter intake (g/kg LW.day) & $17.3 \mathrm{a}$ & $18.8 \mathrm{a}$ & $22.7 b$ & $29.2 \mathrm{c}$ & 0.85 & $* * *$ \\
\hline Water intake (L/day) & $19.3 \mathrm{a}$ & $21.1 \mathrm{a}$ & $24.1 \mathrm{~b}$ & $30.9 \mathrm{c}$ & 1.23 & $* * *$ \\
\hline Water intake (mL/kg LW.day) & $91.2 \mathrm{a}$ & $99.9 \mathrm{a}$ & $112.5 b$ & $144.2 \mathrm{c}$ & 5.39 & $* * *$ \\
\hline Rate constant of disappearance of lithium from plasma (per h) & $0.0130 \mathrm{a}$ & $0.0117 \mathrm{a}$ & $0.0133 \mathrm{a}$ & $0.0258 b$ & 0.00196 & $* * *$ \\
\hline
\end{tabular}

LW, liveweight; means within each row followed by the same letter are not significantly different at $P=0.05$

\footnotetext{
$* * * P<0.001 ;$ n.s., not significant.
} 


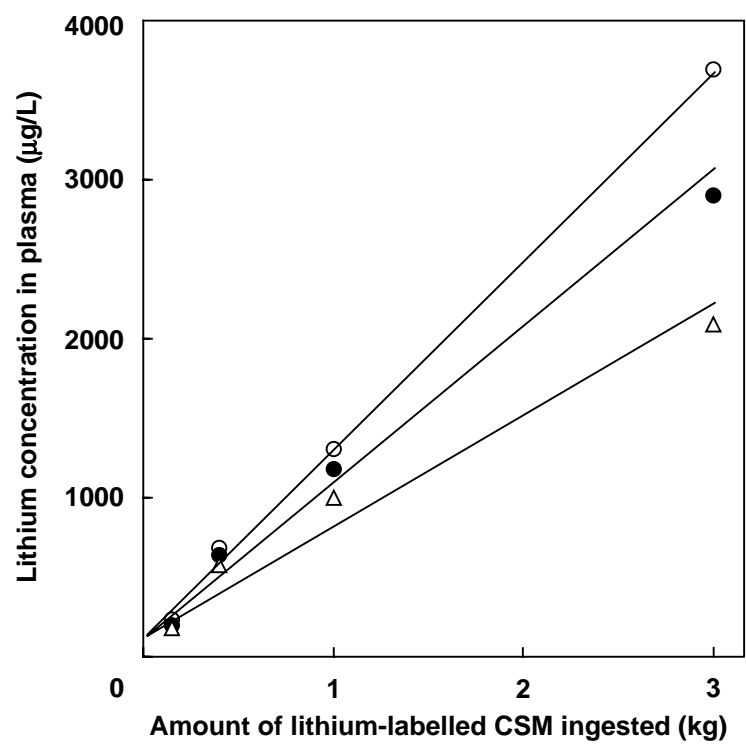

Figure 2. Experiment 1. Relationships between the amount of lithium-labelled cottonseed meal consumed and the concentrations of lithium in plasma after $24(\bigcirc), 32(\bullet)$ and $48(\triangle) \mathrm{h}$.

Because the amount of lithium ingested was confounded with the amounts of CSM, total DM and water ingested (Table 1), it is not possible to conclude whether this difference between diets was due to the amount of lithium ingested or to other differences between the diets. Lithium concentration in plasma after 24,32 and $48 \mathrm{~h}$ was linearly related to the amount of lithium-labelled supplement ingested $(P<0.001, n=32, r=0.86,0.87$ and 0.82 , respectively) (Fig. 2). These relationships after 72 and $96 \mathrm{~h}$ were significantly $(P<0.001)$ curvilinear.
Experiment 2. Intravenous administration of lithium chloride

The hay contained $899 \mathrm{~g} \mathrm{DM} / \mathrm{kg}$ as fed, $927 \mathrm{~g}$ organic matter and $5.3 \mathrm{~g}$ nitrogen per kilogram DM, and had an in vitro organic matter digestibility of $295 \mathrm{~g} / \mathrm{kg} \mathrm{DM}$. CSM contained $933 \mathrm{~g} \mathrm{DM} / \mathrm{kg}$ as fed. Total DM intake was increased $(P<0.001)$ by provision of the higher level of CSM (31.0 and $21.1 \mathrm{~g} \mathrm{DM} / \mathrm{kg} \mathrm{LW.day),} \mathrm{but} \mathrm{hay} \mathrm{intake} \mathrm{was} \mathrm{similar}$ for the 2 treatments (Table 2). Water intake was also increased $(P<0.001)$ by the high level of CSM (155 and $97 \mathrm{~mL} / \mathrm{kg}$ LW.day). Intakes of hay and water during the 3 days before and the 2 days following administration of lithium chloride were similar.

The concentrations of lithium in plasma following intravenous administration are shown in Figure 3. In general, this relationship appeared to be best described by 3 exponential components, but the results for 1 steer offered $3.0 \mathrm{~kg} \mathrm{CSM} /$ day where 3 compartments could not be fitted satisfactorily were considered missing values. The rate constants of the 3 compartments are given in Table 2. The rate constant of disappearance of the lithium from compartment 3 was greater $(P<0.05)$ in steers offered the high than the low level of CSM $(0.0198$ and $0.0105 / \mathrm{h}$, respectively). The $Y$ intercepts of the plasma lithium concentration indicated that the lithium chloride distributed through $18.0 \%$ of the liveweight of the steers.

\section{Experiment 3. Ingestion of supplements or water labelled with lithium}

The steers were in good health throughout the experiment. The hay contained $917 \mathrm{~g} \mathrm{DM} / \mathrm{kg}$ as fed, $878 \mathrm{~g}$ organic matter and $11.2 \mathrm{~g}$ nitrogen per kilogram DM and had an in vitro organic matter digestibility of $497 \mathrm{~g} / \mathrm{kg} \mathrm{DM}$. The cottonseed meal, M3U, LMM-1 and LMM-2 supplements

Table 2. Experiment 2. Intake of hay, cottonseed meal (CSM) and total dry matter (DM), and of water by the steers during the 4 days after intravenous injection of lithium chloride

LW, liveweight

\begin{tabular}{|c|c|c|c|c|}
\hline \multirow[t]{2}{*}{ Measurement } & \multicolumn{2}{|c|}{ Treatment (kg CSM supplement/day) } & \multirow[t]{2}{*}{ s.e.d. } & \multirow[t]{2}{*}{ Signif. } \\
\hline & 0.4 & 3.0 & & \\
\hline$n$ & 4 & 4 & - & - \\
\hline Hay intake (kg DM/day) & 4.61 & 4.39 & 0.29 & n.s. \\
\hline Cottonseed meal intake (kg DM/day) & 0.38 & 2.81 & - & - \\
\hline Total dry matter intake (kg/day) & 4.99 & 7.20 & 0.29 & $* * *$ \\
\hline Hay intake (g DM/kg LW.day) & 19.5 & 18.9 & 0.87 & n.s. \\
\hline Cottonseed meal intake (g DM/kg LW.day) & 1.6 & 12.1 & - & - \\
\hline Total dry matter intake (g/kg LW.day) & 21.1 & 31.0 & 0.99 & $* * *$ \\
\hline Water intake (L/day) & 22.7 & 36.1 & 4.69 & $*$ \\
\hline Water intake (mL/kg LW.day) & 97 & 155 & 18.9 & $*$ \\
\hline \multicolumn{5}{|c|}{ Rate constant of disappearance of lithium from plasma (per h) } \\
\hline Compartment 1 & 0.99 & 1.20 & 0.334 & n.s. \\
\hline Compartment 2 & 0.146 & 0.214 & 0.0813 & n.s. \\
\hline Compartment 3 & 0.0105 & 0.0198 & 0.00322 & $*$ \\
\hline
\end{tabular}

$* P<0.05 ; * * * P<0.001 ;$ n.s., not significant. 


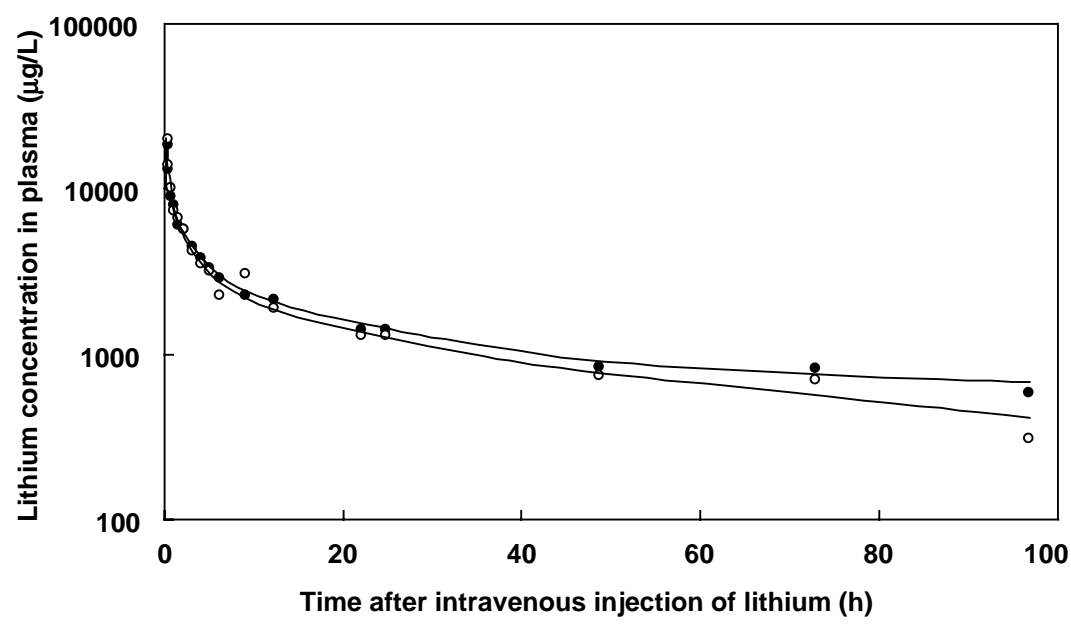

Figure 3. Experiment 2. Mean concentrations of lithium in plasma following intravenous administration of lithium chloride in steers consuming low-quality hay supplemented with $0.4(\bigcirc)$ or $3.0(\bigcirc) \mathrm{kg}$ cottonseed meal per day. Plasma lithium concentrations were adjusted to a normalised intake of $3.0 \mathrm{mg}$ lithium $/ \mathrm{kg}$ liveweight.

contained, on average, 924, 823, 967 and $929 \mathrm{~g} \mathrm{DM} / \mathrm{kg}$ as fed, respectively. Two steers consumed less than $0.9 \mathrm{~g}$ $\mathrm{DM} /$ day of the unlabelled M3U supplement, although mean intake of the other 6 steers was $2.67 \mathrm{~kg} \mathrm{DM} /$ day. Also 3 steers consumed less than $28 \%$ of the offered unlabelled LMM-2 supplement. Since the amounts of lithium marker ingested were much lower than for the other steers $(<0.7 \mathrm{mg} \mathrm{Li} / \mathrm{kg}$ LW) and the consequent low plasma lithium concentrations led to appreciable analytical error, these 5 observations were discarded.

The mean intakes of hay, supplements and water during the 4 days when lithium-labelled supplements or water were ingested and blood samples obtained, are given in Table 3. Intake of hay did not differ $(P>0.05)$ among the treatments, ranging from 15.5 to $16.8 \mathrm{~g} \mathrm{DM} / \mathrm{kg} \mathrm{LW}$. Voluntary intake of M3U supplement was $10.2 \mathrm{~g} \mathrm{DM} / \mathrm{kg} \mathrm{LW}$ and total DM intake was increased $(P<0.001)$ by the provision of this supplement.

Consumption of the lithium-labelled M3U and lithium-labelled water occurred about linearly through the 10-h interval during which they were offered (Fig. 4). However, 78 and $73 \%$ of the lithium-labelled LMM-1 and LMM-2 supplements were consumed within the first hour after being provided to the steers. Provision of lithium-labelled supplement did not appear to change hay or water intake. The change in the concentration of lithium in plasma between 32 and $96 \mathrm{~h}$ after the lithium-labelled supplements were offered to the steers appeared to be satisfactorily described by a single exponential relationship. The concentration of lithium in plasma appeared to be greatest after $24 \mathrm{~h}$ (i.e. $14 \mathrm{~h}$ after removal of the lithium-labelled supplements) (Table 3). Neither the concentrations of lithium in plasma at specific times nor the rate constant of disappearance of lithium from plasma were affected by the dietary treatments (Table 3 ) and were not correlated $(P>0.05)$ with DM or water intake.

\section{Experiment 4. Ingestion of a meal of lithium-labelled molasses supplement}

With 1 exception, the heifers consumed all of the lithium-labelled supplement within $15 \mathrm{~min}$; the heifer that

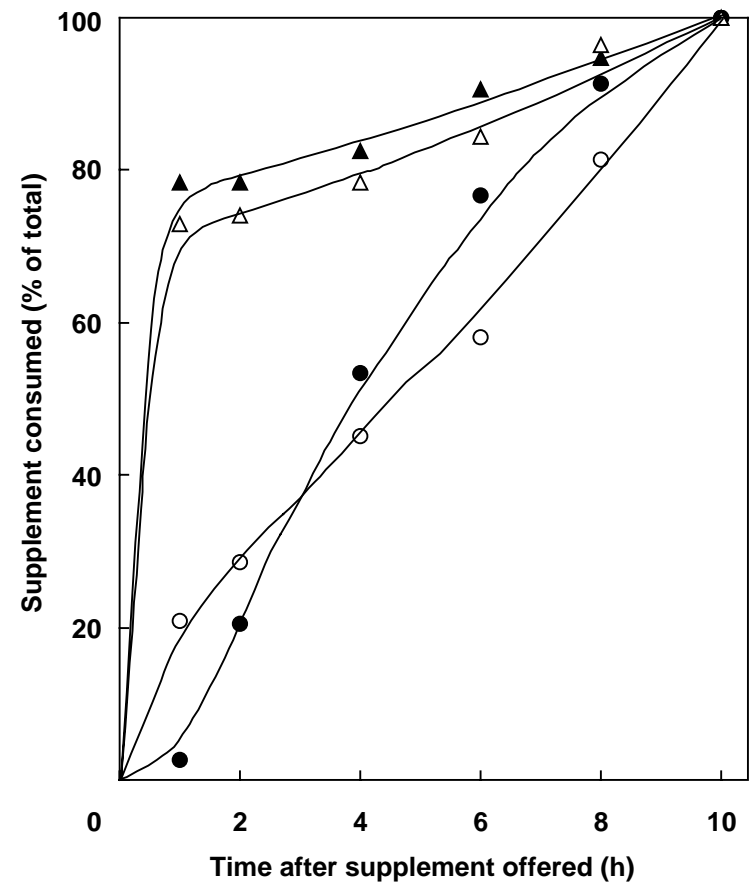

Figure 4. Experiment 3. Intake of 3 lithium-labelled supplements (M3U, O; LMM-1, $\triangle$; LMM-2, $\boldsymbol{\Delta}$ ) or of lithium-labelled water $(\mathbf{O}$ offered at 0800 hours and removed at 1800 hours on one day. On average, the steers consumed $1307 \mathrm{~g} \mathrm{M} 3 \mathrm{U}, 83 \mathrm{~g} \mathrm{LMM-1,} 156 \mathrm{~g}$ LMM-2 and $29.7 \mathrm{~kg}$ water labelled with lithium. 
Table 3. Experiment 3. Intake of hay, supplements and total dry matter (DM), and of water by the steers during the 4 days after ingestion of lithium-labelled supplements

Means within each row followed by the same letter are not significantly different at $P=0.05$ Plasma lithium concentrations were adjusted to a normalised intake of $5.0 \mathrm{mg} \mathrm{Li} / \mathrm{kg}$ liveweight (LW)

\begin{tabular}{|c|c|c|c|c|c|c|}
\hline \multirow[t]{2}{*}{ Measurement } & \multicolumn{4}{|c|}{ Li-labelled supplement or water } & \multirow[t]{2}{*}{ s.e.d. } & \multirow[t]{2}{*}{ Signif. } \\
\hline & M3U & Water & LMM-1 & LMM-2 & & \\
\hline$n$ & 6 & 8 & 8 & 5 & - & - \\
\hline Hay intake (kg DM/day) & 4.10 & 4.34 & 4.40 & 4.40 & 0.140 & n.s. \\
\hline Supplement intake (kg DM/day) & 2.67 & 0.46 & 0.08 & 0.16 & - & - \\
\hline Total dry matter (kg/day) & $6.77^{\mathrm{b}}$ & $4.80^{\mathrm{a}}$ & $4.48^{\mathrm{a}}$ & $4.56^{\mathrm{a}}$ & 0.246 & $* * *$ \\
\hline Hay intake (g DM/kg LW.day) & 15.5 & 16.4 & 16.7 & 16.8 & 0.65 & n.s. \\
\hline Supplement intake (g DM/kg LW.day) & 10.2 & 1.8 & 0.3 & 0.6 & - & - \\
\hline Total dry matter (g/kg LW.day) & $25.7^{\mathrm{b}}$ & $18.2^{\mathrm{a}}$ & $17.0^{\mathrm{a}}$ & $17.4^{\mathrm{a}}$ & 1.28 & $* * *$ \\
\hline Water intake (L/day) & 31.6 & 27.0 & 27.7 & 28.3 & 2.43 & n.s. \\
\hline Water intake (mL/kg LW.day) & 120 & 102 & 105 & 108 & 10.7 & n.s. \\
\hline Amount of $\mathrm{Li}$ ingested $(\mathrm{mg} / \mathrm{kg} \mathrm{LW})$ & 2.44 & 4.28 & 3.99 & 3.75 & - & - \\
\hline \multicolumn{7}{|l|}{ Plasma Li concentration $(\mu \mathrm{g} \mathrm{Li} / \mathrm{L})$} \\
\hline $24 \mathrm{~h}$ & 3965 & 3642 & 3739 & 3108 & 729 & n.s. \\
\hline $32 \mathrm{~h}$ & 3561 & 3560 & 2988 & 2433 & 658 & n.s. \\
\hline $48 \mathrm{~h}$ & 2475 & 2629 & 2256 & 1854 & 424 & n.s. \\
\hline Rate constant of disappearance of lithium from plasma (per h) & 0.0239 & 0.0188 & 0.0156 & 0.0186 & 0.00476 & n.s. \\
\hline
\end{tabular}

$* * * P<0.001 ;$ n.s., not significant.

was the exception consumed only $89 \%$ of that offered. The hay contained $922 \mathrm{~g} \mathrm{DM} / \mathrm{kg}$ as fed, $915 \mathrm{~g}$ organic matter and $4.5 \mathrm{~g}$ nitrogen per kilogram $\mathrm{DM}$, and had an in vitro organic matter digestibility of $310 \mathrm{~g} / \mathrm{kg}$ DM. The molasses supplement contained $590 \mathrm{~g} \mathrm{DM} / \mathrm{kg}$ as fed and $875 \mathrm{~g}$ organic matter and $35 \mathrm{~g}$ nitrogen per kilogram DM. The heifers thus consumed about $38 \mathrm{~g} \mathrm{DM}$ and $1.28 \mathrm{~g}$ nitrogen in the supplement.

Mean voluntary intake of hay for the 2 days following ingestion of the lithium-labelled supplement was 9.35 (s.d. 2.18) $\mathrm{g} \mathrm{DM} / \mathrm{kg} \mathrm{LW}$, while intake of water was 66.9 (s.d. 12.8) $\mathrm{mL} / \mathrm{kg} \mathrm{LW}$. Water intake was related to hay intake as follows:

$$
\begin{gathered}
Y=44.0(\text { s.e. } 10.9)+2.44 \text { (s.e. } 1.14) X, \\
(n=24 ; r=0.37 ; P<0.05 ; \text { r.s.d. }=12.8),
\end{gathered}
$$

where $Y$ is the water intake ( $\mathrm{mL} / \mathrm{kg} \mathrm{LW}$.day) and $X$ is the hay intake (g DM/kg LW.day). Intake of hay was not affected by provision of the lithium-labelled supplement.

The net normalised concentration of lithium in plasma $20 \mathrm{~h}$ after the Li-labelled supplement was consumed [mean 1090 (s.d. 161) $\mu \mathrm{g} \mathrm{Li} / \mathrm{L}$ plasma] was lower $(P<0.01)$ than the concentrations after 24 and $28 \mathrm{~h}$ [mean 1158 (s.d. 190) and 1207 (s.d. 167) $\mu \mathrm{g} \mathrm{Li} / \mathrm{L}$ plasma, respectively] which were not different from each other $(P>0.05)$. Thus, the $\mathrm{CV}$ of lithium concentration among heifers ranged from 13.9 to $16.4 \%$ for the 3 sampling times. The $\mathrm{CV}$ for the means of any 2 of these sampling times was $13.2-14.7 \%$ and the $\mathrm{CV}$ of the mean concentration at the 3 sampling times was $13.8 \%$. The lithium concentrations measured in individual animals were correlated at each combination of the 3 sampling times
$(P<0.001 ; r$ ranged from 0.64 to 0.86$)$. Mean concentration of lithium for the 3 sampling times was related to hay intake as follows:

$$
\begin{gathered}
Y=839 \text { (s.e. } 132)+32.7 \text { (s.e. } 13.8) X \\
(n=24 ; r=0.41 ; P<0.05 ; \text { r.s.d. }=158),
\end{gathered}
$$

where $Y$ is the mean concentration of lithium in plasma $(\mu \mathrm{g} \mathrm{Li} / \mathrm{L})$ and $X$ is the voluntary intake of hay $(\mathrm{g} \mathrm{DM} / \mathrm{kg}$ LW.day). There was no relationship $(P>0.05)$ between mean plasma lithium concentration and water intake.

\section{Discussion}

\section{Kinetics of lithium}

Following intravenous injection, the change in plasma lithium concentration in experiment 2 appeared to be described most adequately by 3 exponential compartments rather than by 2 exponential compartments as reported by Suharyono (1992). However, in the present experiment the plasma lithium concentrations were measured over $96 \mathrm{~h}$, whereas in the studies of Suharyono (1992), the plasma lithium concentration was measured over only $48 \mathrm{~h}$. The third compartment was only evident because of this extended sampling time (Fig. 3). The third compartment appeared to principally represent renal excretion, since most lithium is excreted from the animal by this pathway (Harrison et al. 1963; Ulyatt 1964; Schonewille and Beynen 1999). The first and second compartments observed may have been associated with kinetic compartments of lithium in the extracellular fluid, digesta of the rumen and post-ruminal tract, and other body pools, or with mixing of lithium in 
these pools. Lithium injected intravenously would be expected to enter digesta pools since there is extensive transfer of plasma lithium to the rumen via saliva (Ulyatt 1964; Suharyono 1992).

Following ingestion of lithium-labelled supplement, there was an increase in plasma lithium concentration to a maximum followed by an exponential decline. This was a similar pattern to previous observations with cattle (McLennan 1999) but differed from the results of Suharyono (1992) and Kahn (1994) in sheep where there appeared to be a plateau for some time before the decline in plasma lithium concentration. The time to maximum plasma lithium concentration in the present experiments of about $24 \mathrm{~h}$ is within the range reported in previous experiments; this maximum has been reported to occur after only about $4-12 \mathrm{~h}$ (Kahn 1994; McLennan 1999), 12-24 h (Suharyono 1992), or with fasted sheep $48 \mathrm{~h}$ (Ulyatt 1964). These changes in plasma lithium following ingestion of lithium-labelled supplements are consistent with the observation of 3 kinetic pools of lithium, with the disappearance between 24 and $96 \mathrm{~h}$ principally reflecting renal excretion. The rates of lithium disappearance in experiment 1 when 0.4 and $3 \mathrm{~kg} \mathrm{CSM}$ were consumed $(0.0117$ and $0.0258 / \mathrm{h}$, respectively) were comparable to these rates for compartment 3 measured in the respective diets during experiment $2(0.0111$ and $0.0202 / \mathrm{h}$, respectively). Comparable rate constants were also observed in experiment 3 of the present study. These values compare with a $T_{1 / 2}$ of $29 \mathrm{~h}$ (i.e. a rate constant of $0.024 / \mathrm{h}$ ) observed by McLennan (1999). The rate of disappearance of lithium from plasma is an established procedure to measure specific aspects of renal function and is influenced by a number of factors including sodium excretion (Thomsen 1984; Boer et al. 1988; Koomans et al. 1989).

\section{Measurement of supplement intake by individuals in herds}

The linear relationship observed in experiment 1 between the amount of Li-labelled supplement consumed and plasma lithium concentration is in agreement with previous reports of this relationship in both cattle (McLennan 1999) and sheep (Suharyono 1992; Kahn 1994). Thus, all of these experiments support the hypothesis that lithium salts can be used to estimate intakes of a supplement by individual animals offered a single meal of lithium-labelled supplement, providing that animals are blood-sampled at about the time of maximal plasma lithium concentrations. However, the present studies also indicate that, because the decline in plasma lithium concentration is rapid and exponential, considerable error can be introduced if plasma is sampled some time after the maximum plasma lithium concentration. This error will be exacerbated when the amount of supplement ingested changes the rate of disappearance of lithium from plasma. The $\mathrm{CV}$ of $15 \%$ about the estimation of intake of a meal of lithium-labelled supplement by heifers consuming hay ad libitum in experiment 4 suggests a minimum error in estimation of supplement intake by individual animals. However, this variation is comparable to that of other marker techniques such as chromic oxide to measure intake of supplements and pasture by grazing ruminants (Langlands 1975; Kendall et al. 1980; Parker et al. 1990; Williamson et al. 2000).

Measurements of lithium-labelled supplement intake by individual animals may be made following a single meal if only restricted amounts of a supplement are being provided to a herd. However, where supplements are provided ad libitum, it is clearly desirable that the lithium-labelled supplement should also be provided ad libitum and during an interval representative of the intake of supplement by the herd. As with tritiated water as a marker, if lithium-labelled supplement is provided for some hours during a single day then the estimation of supplement intake may be influenced by differences between animals in the time between ingestion of labelled supplement and blood sampling, and also by the rate constant of disappearance of lithium from the animal (Nolan et al. 1975). For example if lithium-labelled supplements are offered for $9 \mathrm{~h}$, the rate constant of disappearance of lithium is $0.015 / \mathrm{h}$ and the cattle are sampled the following day, calculations indicate that estimated supplement intakes of animals that delayed their entire consumption of lithium-labelled supplement by 3,6 or $9 \mathrm{~h}$ would be 103, 108 and $113 \%$ greater, respectively, than for an animal that consumed all of its lithium-labelled supplement when it was initially offered. This potential error has also been shown experimentally; intake of lithium-labelled supplement given in 5 equal meals over $12 \mathrm{~h}$ was predicted from $24-\mathrm{h}$ blood samples to be $16 \%$ greater than when all of the supplement was consumed as a single meal at the beginning of this interval (McLennan 1999). However, grazing cattle usually spend only part of the day at the water point (Ernst 1973; Squires 1981), so the differences among animals within a herd in the times of ingestion of lithium-labelled supplement offered at the water point are likely to be only several hours. Nevertheless, differences in the time when individual animals consume lithium-labelled supplements offered ad libitum may cause appreciable error in the estimation of individual intakes of supplement.

An alternative procedure to use marker-labelled supplement to measure intake of supplements offered ad libitum is to provide supplement labelled with tritiated water for a week (Nolan et al. 1975) or for many weeks (Wheeler et al. 1980) before blood sampling. The error associated with animals consuming labelled supplement on differing days during the interval when it is offered is directly related to the rate constant of disappearance of the marker from the animal and also to the variation between days in supplement intake (Hedges and Rocks 1980; Dove 1984); as the rate constant of disappearance of tritiated water marker from an animal increased from 0.005 to $0.015 / \mathrm{h}$, the error in 
estimation of intake of labelled supplement offered for a week increased almost 3-fold. Since lithium has a rate constant of disappearance from cattle in the range $0.010-0.025 / \mathrm{h}$ (McLennan 1999; present studies), the errors of this origin in prediction of intake of lithium-labelled supplement consumed for several days will be substantially greater than for tritiated water-labelled supplements. In addition, Dove (1984) showed that as the CV between days in supplement intake increased from 20 to $50 \%$, the error in prediction of supplement intake increased almost 3-fold. Thus, if the experimental procedure involves feeding lithium-labelled supplement for several days, there may be large errors in the measurement of supplement intake by individual animals. Because of these potential errors, we (Dixon and Petherick 1996; Dixon and Smith 2000; Dixon et al. 2000, 2001) have used lithium as a marker of supplement offered for 9-10 $\mathrm{h}$ on a specific day, and accepted that the measured variability in supplement intake relates solely to a specific day. However, it is well established that there is often large variation between days in voluntary intake of loose mineral mix and block supplements (Rocks et al. 1982; Weber et al. 1992; Tait and Fisher 1996). A compromise must be made between greater accuracy if lithium-labelled supplement is offered for only 1 day, and making measurements with lesser accuracy but probably more representative of average intake of supplement over several days. Providing lithium-labelled supplement for at least several days will presumably provide more reliable estimates of the proportion of animals in a herd that do not consume any supplement.

In conclusion, lithium salts can be used to measure intake by individuals of a meal of supplement provided on a specific day. Although errors are likely to be greater, lithium salts can also be used to measure individual intakes of supplements provided ad libitum with sufficient accuracy to be a valuable field technique.

\section{Acknowledgments}

We thank Dr H Mawhinney and Mr E McIlroy of the ICPMS Unit, Animal Research Institute, Yeerongpilly, for the analyses of lithium and Dr Stuart McLennan for comments on the manuscript.

\section{References}

Arnold GW, Maller RA (1974) Some aspects of competition between sheep for supplementary feed. Animal Production 19, 309-319.

Boer WH, Koomans HA, Mees EJD (1988) Renal lithium handling during water loading and subsequent d-DAVP-induced anti-diuresis. European Journal of Clinical Investigation 18, 273-278.

Bowman JGP, Sowell BF (1997) Delivery method and supplement consumption by grazing ruminants: a review. Journal of Animal Science 75, 543-550.

Curtis KMS, Holst PJ, Murray PJ (1994) Measuring supplement intake in the field using ytterbium as a marker. Australian Journal of Experimental Agriculture 34, 339-343.
Dixon RM, Petherick JC (1996) Intake distribution of a range of supplements offered to grazing Bos indicus cross cattle. Animal Production in Australia 21, 442.

Dixon RM, Porch I, White A (2000) Variability in intake of loose mineral mix supplements by grazing heifers. Asian-Australasian Journal of Animal Science 13, Supplement July 2000, B: 228.

Dixon RM, Smith D (2000) Variability in voluntary intake of a molasses-based supplement by cows and calves. Asian-Australasian Journal of Animal Science 13, Supplement July 2000, B: 229.

Dixon RM, Smith DR, Porch I, Petherick JC (2001) Effects of experience of young cattle on their voluntary intake of supplements. Australian Journal of Experimental Agriculture 41, 581-592.

Dove H (1984) Gypsum labelled with tritiated water as a marker for estimating supplement intake by individual sheep fed in groups. Australian Journal of Experimental Agriculture 24, 484-493.

Dove H, Mayes RW (1991) The use of plant wax alkanes as marker substances in studies of the nutrition of herbivores: a review. Australian Journal of Agricultural Research 42, 913-952.

Du Toit JT, Provenza FD, Nastis A (1991) Conditioned taste aversions: how sick must a ruminant get before it learns about toxicity in foods? Applied Animal Behaviour Science 30, 35-46.

Ducker MJ, Kendall PT, Hemingway RG, McClelland TH (1981) An evaluation of feedblocks as a means of providing supplementary nutrients to ewes grazing upland/hill pastures. Animal Production 33, 51-57.

Eggington AR, McCosker TH, Graham CA (1990) Intake of lick block supplements by cattle grazing native monsoonal tallgrass pastures in the Northern Territory. Australian Rangeland Journal 12, 7-13.

Ernst AJ (1973) Some observations on the behaviour of beef cattle at urea-molasses feeders. Journal of the Australian Institute of Agricultural Science 39, 266-268.

Foot JZ, Russel AJF, Maxwell TJ, Morris P (1973) Variation in intake among group-fed pregnant Scottish Blackface ewes given restricted amounts of food. Animal Production 17, 169-177.

Harrison FA, Hill KJ, Mangan JL (1963) Absorption and excretion of lithium and magnesium in sheep. The Biochemical Journal 89, 99-100.

Hedges DA, Rocks RL (1980) A simulation study of the use of radioactive tracers for predicting intake of supplements. Animal Production in Australia 13, 487.

Holechek JL, Vavra M, Pieper RD (1982) Methods for determining the nutritive quality of range ruminant diets: a review. Journal of Animal Science 54, 363-376.

Holst PJ, Hall DG, Nolan JV (1996) Estimations of pasture and grain intake of prepartum single- and twin-bearing ewes. Australian Journal of Experimental Agriculture 36, 529-532.

Kahn LP (1994) The use of lithium chloride for estimating supplement intake in grazing sheep. Australian Journal of Agricultural Research 45, 1731-1739.

Kendall PT, Ducker MJ, Hemingway RG (1980) Individual intake variation by cattle given self-help feed blocks or cubed concentrate fed in troughs. Animal Production 30, 485.

Koomans HA, Boer WH, Mees EJD (1989) Evaluation of lithium clearance as a marker of proximal tubule sodium handling. Kidney International 36, 2-12.

Kotb AR, Luckey TD (1972) Markers in nutrition. Nutrition Abstracts and Reviews 42, 813-845.

Langlands JP (1975) Techniques for estimating nutrient intake and its utilization by the grazing ruminant. In 'Digestion and metabolism in the ruminant'. (Eds IW McDonald, ACI Warner) pp. 320-332. (University of New England Press: Armidale) 
Lobato JFP, Pearce GR, Tribe DE (1980) Measurement in the variability in intake by sheep of oat grain, hay and molasses-urea blocks using chromic oxide as a marker. Australian Journal of Experimental Agriculture and Animal Husbandry 20, 413-416.

McLennan SR (1999) New techniques for estimating supplement intake by grazing herbivores. In 'Nutritional ecology of herbivores. Satellite symposium. Emerging techniques for studying the nutrition of free ranging herbivores'. (Eds H Dove, SW Coleman). (San Antonio, TX) CD-ROM.

Murray RM, Graham C, Round J, Bond J (1978) Intake and response to phosphorus supplements by range cattle. In 'Proceedings of the first international rangeland congress'. (Ed. DN Hyder) pp. 427-428. (Society of Rangeland Management: Denver, CL)

National Research Council (1996) 'Nutrient requirements of beef cattle (7th edn).' (National Academy Press: Washington, DC)

Nolan JV, Norton BW, Murray RM, Ball FM, Roseby FB, Rohan-Jones W, Hill MK, Leng RA (1975) Body weight and wool production in grazing sheep given access to a supplement of urea and molasses: intake of supplement/response relationships. Journal of Agricultural Science, Cambridge 84, 39-48.

Parker WJ, Morris ST, Garrick DJ, Vincent GL, McCutcheon SN (1990) Intraruminal chromium controlled release capsules for measuring herbage intake in ruminants - a review. Proceedings of the New Zealand Society of Animal Production 50, 437-442.

Patterson HD, Thompson R (1971) Recovery of inter-block information when block sizes are unequal. Biometrika 58, 545-554.

Rocks RL, Wheeler JL, Hedges DA (1982) Labelled waters of crystallization in gypsum to measure the intake by sheep of loose and compressed mineral supplements. Australian Journal of Experimental Agriculture and Animal Husbandry 22, 35-42.

Schonewille JT, Beynen AC (1999) Lithium chloride as a reference substance for urine collection in goats. New Zealand Veterinary Journal 47, 150-151.

Shipley RA, Clarke RA (1972) 'Tracer methods for in vivo kinetics.' (Academic Press: New York and London)
Squires V (1981) 'Livestock management in the arid zone.' (Inkata Press: Melbourne)

Suharyono (1992) 'Estimation of dietary intake in sheep using lithium as a marker.' MSc Thesis, University of New England, Armidale, Australia.

Suharyono, Nolan JV, Kent J (1991) Estimation of supplement intake in individual grazing ruminants using lithium chloride as a marker. In 'Recent advances in animal nutrition in Australia'. (Ed. DJ Farrell) p. 16A. (University of New England Publishing Unit: Armidale, NSW)

Tait RM, Fisher LJ (1996) Variability in individual animal's intake of minerals offered free-choice to grazing ruminants. Animal Feed Science and Technology 62, 69-76.

Thomsen K (1984) Lithium clearance: a new method for determining proximal and distal tubular resorption of sodium and water. Nephron 37, 217-223.

Ulyatt MJ (1964) The suitability of lithium as a marker for estimating rumen water volume in sheep. New Zealand Journal of Agricultural Research 7, 774-778.

Weber DW, Dill TO, Oldfield JE, Frobish R, Vanderbergh K, Zollinger W (1992) Block intake by beef cattle. The Professional Animal Scientist 8, 15-30.

Wheeler JL, Rocks RL, Hedges DA (1980) Intake of mineral supplements and productivity of sheep grazing sorghum. Animal Production in Australia 13, 297-300.

Williamson PJ, Hennessy DW, Gogel BJ, Barlow R (2000) The estimation of faeces output in penned cattle by controlled release of chromium oxide and the subsequent accuracy of prediction forage intake with in vitro digestibility. Journal of Agricultural Science, Cambridge 135, 297-304.

Received 12 September 2001, accepted 7 May 2002 